International Review of Research in Open and Distributed Learning Volume 19, Number 3

July -2018

\title{
Social Media Adoption by the Academic Community: Theoretical Insights and Empirical Evidence From Developing Countries
}

\author{
Mamoona Arshad ${ }^{1}$ and Muhammad Shakaib Akram ${ }^{2}$ \\ ${ }^{1}$ Suleman Dawood School of Business, LUMS, Pakistan, ${ }^{2}$ College of Business Administration, King Saud University, Saudi \\ Arabia
}

\begin{abstract}
The paper investigates the impact of virtual environmental characteristics such as collaboration, communication, and resource sharing on social media adoption by the academic community at the university level. Building on the social constructivist paradigm and technology acceptance model, we propose a conceptual model to assess social media adoption in academia by incorporating collaboration, communication, and resource sharing as predictors of social media adoption, whereas perceived ease of use and perceived usefulness act as mediators in this relationship. Structural equation modeling serves to estimate the proposed conceptual model on a sample of 661 respondents from the Kingdom of Saudi Arabia and Pakistan. The findings suggest that an individual's propensity toward social media features (i.e., collaboration, communication, and resource sharing) acts as a stimulus to their social media adoption. Moreover, perceived ease of use and perceived usefulness mediate the relationship between these stimuli and their outcomes (i.e., social media adoption). The paper concludes with the discussion on the findings and recommendations for the academicians and the practitioners of social media in the higher education institutions.
\end{abstract}

Keywords: collaboration, communication, resource sharing, social media, academia 


\section{Introduction}

Due to easy access to the internet, the use of social media has massively increased in recent years (Karikari, Kofi, \& Owusu-Frimpong, 2017). The internet usage has exponentially grown in the past decade, and more than half of world population have access to the internet (Internet World Stats, 2018). Majority of the internet users are also regular users of social media platforms such as Facebook, Twitter, LinkedIn, and YouTube. In the past decade, these social media platforms have become extremely popular mainly due to the content sharing capability of Web 2.0 technology. According to the latest social media statistics, there are more than 2 billion Facebook users, more than 300 million Twitter users, more than 500 million Google+ users, and more than 400 million LinkedIn users (InternetLiveStats, 2018). Above statistics show an emerging trend of social media usage around the globe. Although social media platforms were initially created for the social communication and social interaction, over time academics have realized the advantages of these tools over the traditional communication tools (e.g., university email) in their professional activities, due to certain features such as ease of use and usefulness for collaboration and communication (Berger, 2017; Forbes, 2017; Tess, 2013). However, although social media is rapidly penetrating into the society, there is no consensus in the literature on the drivers of social media adoption in an academic context. Moreover, it is not clear how social media can impact academic performance. While there are studies showing the effective role of social media in academic performance at higher education (Sobaih, Moustafa, Ghandforoush, \& Khan, 2016), some argue that there is no significant relationship between social media usage and academic performance (Lau, 2017). Therefore, there is a need to further investigate underlying motives behind social media adoption by the academic community (e.g., students, researchers, and faculty). This study is an attempt to explore the motivators behind an individuals' social media adoption in academic institutions at the university level.

Generally, the social media users are those individuals who wish to interact and collaborate with other members through the virtual community (Hrastinski \& Aghaee, 2012). Despite this fact, underlying motives of social media usage for educational purposes is relatively less explored (Hrastinski \& Aghaee, 2012). Moreover, the previous discussions are ambiguous in suggesting the key determinants of social media, i.e., the elements which narrate into learning, knowledge, and education (Selwyn, 2012). Though there is evidence of research on topics focusing on social media adoption from various perspectives (Hopp \& Gangadharbatla, 2016; Kwahk \& Park, 2016; Maresh-Fuehrer \& Smith, 2016; Zolkepli \& Kamarulzaman, 2015), the research on social media adoption in the context of higher education is still limited (ForkoshBaruch \& Hershkovitz, 2012). Therefore, considering academic community among the main users of social media for sharing their explicit and tacit knowledge (Chen \& Bryer, 2012; Tess, 2013), this study aims to explore the stimuli that provoke social media adoption by the academic community. The study hence strives to develop and validate the adoption of social media, by the academic community, through integrating important motivational determinants of social media.

An efficient application of modern social technology with social media tools can be in developing collaborative learning environment based on the social constructivist paradigm. Social media platforms have significant capability to support the social constructivist paradigm that promotes collaborative learning (Vygotsky, 1978). Web 2.0 technologies pave the way to social and collaborative learning by facilitating communication, collaboration, and resource sharing in an easy and interesting manner through 
social media platforms (Mbati, 2013). Therefore, building on the social constructivist paradigm (Vygotsky, 1978) and technology acceptance model (Davis, 1989), this research aims to investigate the role of social and technological factors leading to social media adoption by the academic community. Specifically, we want to investigate how collaboration, communication and resource sharing capabilities of social media platforms may stimulate the individuals' social media adoption and how users' technology-related beliefs (i.e., perceived ease of use and usefulness) of social media may intervene the relationship between this stimulus and social media adoption in an academic context.

Drawing on the technology acceptance model (Davis, 1989) and social constructivist paradigm (Vygotsky, 1978), the study contributes to literature (1) by proposing a Social Media Adoption Model (SMAM) for the academic community, and (2) by empirically validating this model with data from Kingdom of Saudi Arabia (KSA) and Pakistan. In this model, collaboration, communication, and resource sharing have been identified as the stimuli to social media adoption; whereas, perceived usefulness and perceived ease of use have emerged as the mediators. Additionally, past social media experience with social media platforms is found to have a significant effect on academicians' social media adoption.

The paper is organized as follows. First, the theoretical background is discussed followed by hypotheses development for each construct. Next, research methodology, measures, and procedure are explained. Then, data analysis and results are presented. Finally, the article concludes by a discussion on the results, followed by its limitations and potential future directions.

\section{Theoretical Background}

In the past decade, social media platforms have significantly changed the ways of communication and collaboration in the society. Such web-based technologies are being accepted worldwide and their usage has also emerged in the higher education sector providing the bulk of information through technological innovation (Wankel, 2009). Social media platforms provide an easy alternative, to the academic community, as compared to official communications such as email and blackboard. Thus, it is emerging as a new communication and collaboration tool among the academic community in higher education institutions (Roblyer, McDaniel, Webb, Herman, \& Witty, 2010). Social media has greatly changed the communication/feedback environment by introducing technologies that have modified the educational perspective of learning and interacting (Prensky, 2001).

Literature provides evidence of social media usage as an essential learning component for academic communities in higher education (Chen \& Gilchrist, 2013). Social media has facilitated not only students but also researchers and educators by providing them with a platform to collaborate and communicate. Currently, social media platforms are being effectively used by the academic community in a variety of ways, such as through blogs and sharing of educational videos, updates, and academic documents (Berger, 2017). There is no doubt in the critical role that faculty play in facilitating and guiding their students; social media can facilitate this student-teacher relationship and hence, enhance the overall learning experience (Sobaih et al., 2016; Tess, 2013) . Faculty might attempt to strengthen their students' learning experience by integrating online networks support and interesting features such as informal learning (Mazman \& Usluel, 
2010; Sánchez, Cortijo, \& Javed, 2014). Forkosh-Baruch and Hershkovitz (2012) have suggested that social networking sites promote knowledge/information sharing through providing a collaborative platform for the academic institutions. Literature suggests that despite the excessive research on higher education and its link to social media and its various tools, the gap regarding the drivers which promote an individual to adopt social media still requires further research (Hu \& Hui, 2012). This research is an attempt to address these issues.

\section{Hypotheses Development}

Historically, the Theory of Reasoned Action (Fishbein \& Ajzen, 1975) and the Technology Acceptance Model (Davis, 1989) have been used to assess individuals' acceptance and use of technology. According to the Technology Acceptance Model, perceived usefulness and perceived ease are the main determinants of an individual's behavioral intentions and actual usage (Davis, 1989). The following section reflects how perceived usefulness, perceived ease of use, collaboration, communication, and resource sharing are related to social media adoption.

\section{Perceived Usefulness}

Perceived usefulness, derived from the Technology Acceptance Model (TAM), is the particular level that an individual perceives that they can improve their job performance or create ease in attaining the targeted goals by using an information system. It is also believed to make an individual free from mental pressure (Davis, 1989). Consistently, perceived usefulness has been considered as a strong predictor for the adoption of technology (Jiang, Hsu, Klein, \& Lin, 2000). The literature supports that TAM helps in assessing and predicting the use of technology in academia ( $\mathrm{Lu}, \mathrm{Yao}, \& \mathrm{Yu}, 2005)$. Therefore, we encompass perceived usefulness of the social media as a substantial predictor of social media adoption in education. As such, we hypothesize:

Hypothesis 1: Perceived usefulness of social media positively affects social media adoption.

\section{Perceived Ease of Use}

Perceived ease of use can be defined as the level to which an individual believes that using a specific system will make a task easier (Gruzd, Staves, \& Wilk, 2012) and will reduce mental exertion (Davis, 1989). Venkatesh (2000) posits this construct as a vital element in determining a user's behavior toward technology. Though generally, there is consensus on the positive effect of perceived ease of use and perceived usefulness on users' attitude towards social media, it is not yet clear which one of these is more relevant in explaining users' attitude towards social media in the academic community (Lowry, 2002). Perceived ease of use is one of the eminent behavioral beliefs affecting the users' intention toward technology acceptance ( $\mathrm{Lu}$ et al., 2005). The literature suggests that perceived ease of use of technology develops a positive attitude toward its usage (Davis, 1989). Therefore, we posit that a users' perception of the ease of use of social media will play an important role in forming their positive attitude toward social media and will eventually result in social media adoption. Hence, we hypothesize:

Hypothesis 2a: Perceived ease of use of social media positively affects social media adoption. 
Hypothesis 2b: Perceived ease of use of social media positively affects its perceived usefulness.

\section{Collaboration}

Social media platforms have thoroughly transformed the ways of communications by offering collaborative and shared learning experiences. The beneficiaries are not only the general public but also the academic community (Kaplan \& Haenlein, 2010). Collaborative learning is considered as an essential instructional method as it assists in overcoming the communication gap among the academic community (Bernard, Rubalcava, \& St-Pierre, 2000). The academic community utilizes various social media platforms with the intention to socialize and communicate with others and to share common interests (Sánchez et al., 2014; Sobaih et al., 2016). The exchange of information through social media platforms help the academic community to develop an easy and effective communication among classmates and colleagues (Kaplan \& Haenlein, 2010). Social media platforms can also help in developing communities of practice that may help improve collaboration and communication among members of the community (Sánchez et al., 2014). Evidence from previous work confirms that social media platforms are beneficial to college and university students for education purposes (Forkosh-Baruch \& Hershkovitz, 2012). Due to the intrinsic ease of use and usefulness of social media, academics are regularly using information and communication technologies, especially social media, for collaboration with colleagues in one way or the other (Koh \& Lim, 2012; Wang, 2010). On the basis of above justification, the following hypotheses have been formulated:

Hypothesis 3a: Perceived usefulness mediates the relationship between collaboration and social media adoption.

Hypothesis 3b: Perceived ease of use mediates the relationship between collaboration and social media adoption.

\section{Communication}

Social Media offers a platform to communicate via sending and receiving messages, which can also be used by the academic community to exchange information and knowledge (Kaplan \& Haenlein, 2010). Various researchers have proposed the adoption of social media as a way of communication for the academic community. Among these, Wankel (2009) and Gruzd et al. (2012) proposed that social media can promote healthy communication for learners through social media tools and apps, hence providing the academic community with new means of learning and knowledge creation. Faculty can use social media to communicate with their students effectively; teachers can create discussion groups where students can share their thoughts and questions with their classmates and seek guidance from their teacher. Unlike official communication channels such as email, these days, people are more active on social media which can also help the academic community quickly disseminate any important information. For the academic community, this mode of communication seems promising because it helps them to collaborate and engage with the community members. We argue that the users' perceived ease of use and usefulness of social media will positively influence their social media adoption and will also strengthen the relationship between communication and social media adoption. Hence, our hypotheses are:

Hypothesis 4a: Perceived usefulness mediates the relationship between communication and social media adoption. 
Hypothesis 4b: Perceived ease of use mediates the relationship between communication and social media adoption.

\section{Resource Sharing}

Resource sharing refers to an individual's agreement to sharing their resources, such as ideas and academic material with others through social media platforms (Bock, Zmud, Kim, \& Lee, 2005). Social media platforms allow for the sharing and dissemination of user-generated content and resources (Kaplan \& Haenlein, 2010), as a medium that facilitates knowledge seekers and knowledge providers in learning and teaching by providing them a collaborative environment (Selwyn, 2012). The literature suggests that social media promotes knowledge/information sharing through providing collaborative platforms for dissemination of online learning resources (Forkosh-Baruch \& Hershkovitz, 2012). It alludes to the point that activities through social networks and social media tools facilitate resource sharing; as learners perceive this medium to be easy to use and useful because it helps them share their knowledge and resources to the relevant person more effectively and efficiently (Mazer, Murphy, \& Simonds, 2007). We posit that:

Hypothesis 5a: Perceived usefulness mediates the relationship between resource sharing and social media adoption.

Hypothesis 5 b: Perceived ease of use mediates the relationship between resource sharing and social media adoption.

\section{Covariates}

We incorporated individuals' demographics such as age, gender, and social media experience as covariates because these variables are known to impact the individuals' social media adoption.

The proposed Social Media Adoption Model (Figure 1) summarizes the relationships among the proposed stimuli of social media usage (i.e., collaboration, communication and resource sharing) their outcome (social media adoption) and the proposed mediators (perceived usefulness and perceived ease of use) along with the control variable (age, gender, social media experience). 


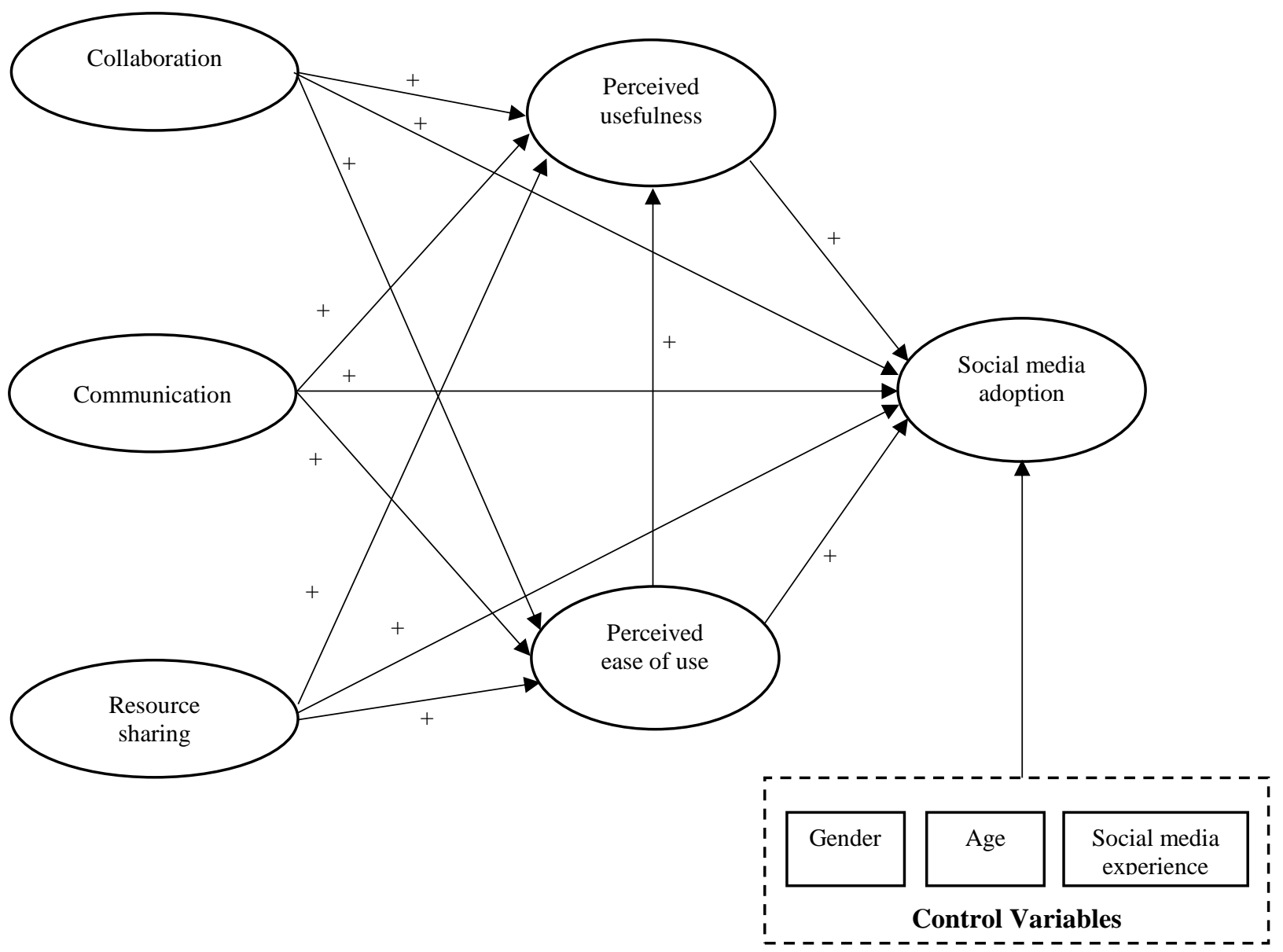

Figure 1. Social Media Adoption Model (SMAM).

\section{Methodology}

\section{Measures and Procedure}

All the items to measure latent variables have been designed on the basis of technology acceptance literature and are adapted in the context of social media adoption by the academic community. Each construct, in this study, has been measured by four items each anchored on a 5 -point Likert scale ( $1=$ Strongly Disagree to $5=$ Strongly Agree). The final items in the questionnaire are presented in Appendix A.

Data was gathered from the academic community with special emphasis on higher education institutions in KSA and Pakistan. Before the final data collection, a pretest was conducted with 50 participants in both countries to assess the reliability and validity of the constructs. The results of the pretest indicated adequate reliability of the scales as the Cronbach's alpha values for each scale were above 0.70 (Gerbing \& Anderson, 1988). Following convenience sampling approach, respondents of both countries were approached in large 
universities at various places within the university campuses such as classrooms, coffees shops, and faculty offices.

\section{Sample Demographics}

A total of 661 responses were collected (326 from Pakistan and 335 from KSA) for the empirical testing of the conceptual model. The respondents' ages range from 17 to 40 years in both countries. The Pakistani sample comprises of $51 \%$ females and $49 \%$ males; whereas, the Saudi sample consists of $43.6 \%$ females and $56.4 \%$ males. The majority of respondents (82\%) logged into social media websites daily. In the Pakistani sample, only $3.1 \%$ of the respondents were undergraduates; $53.6 \%$ were graduates, and $43.3 \%$ were postgraduates while in the Saudi sample $61.2 \%$ of the respondents were undergraduates, $28.1 \%$ were graduates, and $10.7 \%$ were postgraduates. The subjects report that they utilize social media in their studies, research and academic career, and 5.2\% reported that they never used social media for academic purposes as they believe that social media is for the personal use and not for education-related activities. Concerning the social media usage experience: in the Pakistani sample, $27.3 \%$ identified as expert users, $46 \%$ as intermediate users, and $26.7 \%$ as beginners; whereas, in the Saudi sample $29.6 \%$ identified as expert users 48.1\% as intermediate users, and $\mathbf{2 2 . 4 \%}$ as beginners. In both countries, the most preferred social media platform for educational purposes include Facebook, LinkedIn, YouTube, and Twitter.

\section{Data Analysis}

The data analysis is carried out in two phases. The psychometric properties (i.e., reliability and validity) of the adapted measures were examined in the first phase using confirmatory factor analysis (CFA), while the proposed relationships among latent variables were tested through the structural model in the second phase. Multiple measures such as normed chi-square $\left(\chi^{2}\right)$, Goodness of Fit Index (GFI), Adjusted Goodness of Fit Index (AGFI), Comparative Fit Index (CFI), Tucker-Lewis Index (TLI), and Root Mean Square Error of Approximation (RMSEA) were used to analyze the model fit (Hu \& Bentler, 1999).

\section{Confirmatory Factor Analysis}

We estimate psychometric properties of the adapted measures by multi-group confirmatory factor analysis (CFA) using AMOS 23. The fit indices of the measurement model $\left(\chi^{2}=900.97, \mathrm{df}=474, \chi^{2} / \mathrm{df}=1.90, \mathrm{GFI}=\right.$ $0.89, \mathrm{AGFI}=0.87, \mathrm{CFI}=0.96, \mathrm{TLI}=0.95, \mathrm{RMSEA}=0.04)$ illustrate an adequate fit. The reliability and validity of the scales were assessed through results of the measurement model. Composite reliability (CR) along with Cronbach's alpha values were assessed to examine the reliability of the scale. Both the composite reliability and Cronbach's alpha values were above 0.8 , indicating strong internal reliability and consistency of each adapted measure (see Table 1).

Following Fornell and Larcker (1981), the convergent and discriminant validity was established. The results in Table 1 show that the average variance extracted (AVE) values (diagonal entries) for each construct are greater than 0.5 for both the countries and are also greater than shared variances (off-diagonal entries). 


\section{Common Method Variance (CMV)}

We used Harman's single factor test and common latent factor method to verify the presence of any CMV. The variance explained by an un-rotated single factor is $36 \%$, i.e., it remains within the acceptable limit of $50 \%$ for the absence of CMV (Podsakoff, MacKenzie, Lee, \& Podsakoff, 2003). The fit indices $\left(\chi^{2}=2372.72\right.$, $\mathrm{df}=252, \chi^{2} / \mathrm{df}=9.41, \mathrm{GFI}=0.72, \mathrm{AGFI}=0.67, \mathrm{CFI}=0.79, \mathrm{TLI}=0.77, \mathrm{RMSEA}=0.12$ ) of the single latent factor model reveal a poor model fit, suggesting no threat of CMV.

Table 1

Convergent and Discriminant Validity

\begin{tabular}{|c|c|c|c|c|c|c|c|}
\hline CR & Constructs & $\mathrm{COL}$ & $\mathrm{COM}$ & $\mathrm{RS}$ & $\mathrm{PU}$ & PEU & KSI \\
\hline \multirow[t]{2}{*}{$0.88(0.85)$} & Collaboration (COL) & $0.65(0.6)$ & 0.54 & 0.36 & 0.50 & 0.44 & 0.55 \\
\hline & Communication & & & & & & \\
\hline $0.83(0.86)$ & $(\mathrm{COM})$ & 0.26 & $0.54(0.6)$ & 0.44 & 0.57 & 0.51 & 0.60 \\
\hline \multirow[t]{2}{*}{$0.81(0.84)$} & Resource Sharing (RS) & 0.28 & 0.51 & $0.52(0.57)$ & 0.44 & 0.36 & 0.54 \\
\hline & Perceived Usefulness & & & & & & \\
\hline $0.86(0.89)$ & (PU) & 0.30 & 0.36 & 0.34 & $0.61(0.67)$ & 0.56 & 0.65 \\
\hline \multirow[t]{2}{*}{$0.82(0.89)$} & $\begin{array}{l}\text { Perceived Ease of Use } \\
\text { (PEU) }\end{array}$ & 0.39 & 0.51 & 0.43 & 0.40 & $0.54(0.66)$ & 0.58 \\
\hline & Social media adoption & & & & & & \\
\hline $0.89(0.90)$ & (SMA) & 0.41 & 0.50 & 0.48 & 0.50 & 0.54 & $0.66(0.7)$ \\
\hline
\end{tabular}

Note. CR: Composite reliability, Diagonal elements are Average variance extracted and below (above) the diagonal are shared variances for Pakistan (KSA) data. The values in the parentheses are for KSA.

\section{Structural Regression Model}

The structural equation modeling (SEM) technique, a multi-group structural regression model, was employed through AMOS 23 to measure the proposed relationships of the conceptual model. The model shows a good fit as depicted by the fit indices $\left(\chi^{2}=1365.16, \mathrm{df}=537, \chi^{2} / \mathrm{df}=2.54, \mathrm{GFI}=0.84, \mathrm{AGFI}=0.89\right.$, $\mathrm{CFI}=0.92$, TLI $=.91$, RMSEA $=.04)$. Overall, the adequacy of model fit allows us to further analyze our hypotheses.

\section{Direct Effects}

Table 2 presents the structural model results of the direct effects, for both the countries. H1 and H2a posit the positive impact of perceived usefulness (PU) and perceived ease of use (PEU) of social media on social media adoption (SMA). The results indicate that, in both countries, $\mathrm{PU}(\beta=.25, \mathrm{p}<.01 ; \beta=.34, \mathrm{p}<.001)$ and $\operatorname{PEU}(\beta=.23, \mathrm{p}<.01 ; \beta=.25, \mathrm{p}<.01)$ of social media have a significant positive effect on SMA. The results suggest that PU is slightly higher in KSA than in Pakistan, while, PEU is almost the same for both samples; hence, providing support for $\mathrm{H}_{1}$ and H2a. H2b also finds support, in both samples, for the positive association between the PEU and PU $(\beta=.40, \mathrm{p}<.001 ; \beta=.24, \mathrm{p}<.01)$. The collaboration (COL), communication (COM) and resource sharing (RS) have a significant positive effect on PU and PEU. Moreover, the direct effects of COL and RS on social media adoption are also found to be positive and 
significant for both samples. However, the impact of COM on SMA is significant for the KSA sample but not for the Pakistani sample.

Concerning the impact of control variables (i.e., gender, age, experience), we do not find any significant impact of gender and age on social media adoption in both samples. However, social media experience is found to have significant positive effects on social media adoption in both samples. This suggests that the individuals having more experience with social media usage may show more favorable attitude to adopt social media than the ones having relatively less experience. Table 2 summarizes all the direct effects proposed in the conceptual model.

Table 2

Direct Effects

\begin{tabular}{lcccc}
\hline Relationship & \multicolumn{2}{c}{ Pakistan } & \multicolumn{2}{c}{ KSA } \\
\cline { 2 - 5 } & Non-Std. Est & Std Est & Non-Std. Est & Std Est \\
\hline PU $\rightarrow$ SMA & $0.25^{* *}$ & 0.26 & $0.34^{* * *}$ & 0.26 \\
PEU $\rightarrow$ SMA & $0.23^{* *}$ & 0.21 & $0.25^{* *}$ & 0.20 \\
PEU $\rightarrow$ PU & $0.40^{* * * *}$ & 0.33 & $0.24^{* *}$ & 0.25 \\
COL $\rightarrow$ PU & $0.24^{* *}$ & 0.19 & $0.15^{*}$ & 0.21 \\
COL $\rightarrow$ PEU & $0.28^{* *}$ & 0.26 & $0.24^{* *}$ & 0.32 \\
COL $\rightarrow$ SMA & $0.21^{*}$ & 0.18 & $0.19^{*}$ & 0.20 \\
COM $\rightarrow$ PU & $0.31^{* *}$ & 0.27 & $0.17^{*}$ & 0.19 \\
COM $\rightarrow$ PEU & $0.39^{* * *}$ & 0.40 & $0.39^{* * *}$ & 0.42 \\
COM $\rightarrow$ SMA & $0.14^{\text {ns }}$ & 0.12 & $0.20^{* *}$ & 0.17 \\
RS $\rightarrow$ PU & $0.20^{*}$ & 0.17 & $0.18^{*}$ & 0.18 \\
RS $\rightarrow$ PEU & $0.18^{*}$ & 0.18 & $0.20^{* *}$ & 0.19 \\
RS $\rightarrow$ SMA & $0.28^{* *}$ & 0.25 & $0.25^{* *}$ & 0.18 \\
Gender $\rightarrow$ SMA & $0.09^{\text {ns }}$ & 0.05 & $0.04^{\mathrm{ns}}$ & 0.02 \\
Age $\rightarrow$ SMA & $0.01^{\text {ns }}$ & 0.03 & $-0.04^{\mathrm{ns}}$ & -0.03 \\
SME $\rightarrow$ SMA & $0.07^{*}$ & 0.09 & $0.10^{*}$ & 0.14 \\
\hline
\end{tabular}

Note. ${ }^{*} \mathrm{p}<0.05,{ }^{* *} \mathrm{p}<0.01,{ }^{* * *} \mathrm{p}<0.001 . \mathrm{ns}=$ not significant, SME: Social media usage experience, $\mathrm{PU}=$ perceived usefulness, $\mathrm{PEU}=$ perceived ease of use, $\mathrm{SMA}=$ social media adoption, $\mathrm{COL}=$ collaboration, $\mathrm{COM}=$ communication and RS=resource sharing.

\section{Mediated Effects}

SEM has been used for estimation of the multi-mediation model. A phantom model approach (Macho \& Ledermann, 2011) was used to test the specific effects of all the independent variables on the dependent variable through each of mediating variables. Table 3 exhibits that the indirect effects of all independent variables on the dependent variable through each of the mediators are significant for both samples at $\mathrm{p}<.05$ except for the indirect effect of resource sharing through perceived ease of use (for the Pakistani sample) which is significant at $\mathrm{p}<.10$. 
Table 3

Indirect Effects

\begin{tabular}{lcccccc}
\hline Relationship & \multicolumn{3}{c}{ Pakistan } & & \multicolumn{2}{c}{ KSA } \\
\cline { 2 - 7 } & Estimate & LB & UB & Estimate & LB & UB \\
\hline COL $\rightarrow$ PU $\rightarrow$ SMA & $0.07^{*}$ & 0.00 & 0.13 & $0.05^{*}$ & 0.02 & 0.09 \\
COL $\rightarrow$ PEU $\rightarrow$ SMA & $0.06^{*}$ & 0.02 & 0.12 & $0.06^{*}$ & 0.02 & 0.13 \\
COM $\rightarrow$ PU $\rightarrow$ SMA & $0.08^{*}$ & 0.03 & 0.17 & $0.06^{*}$ & 0.02 & 0.15 \\
COM $\rightarrow$ PEU $\rightarrow$ SMA & $0.09^{*}$ & 0.04 & 0.16 & $0.11^{*}$ & 0.03 & 0.23 \\
RS $\rightarrow$ PU $\rightarrow$ SMA & $0.06^{*}$ & 0.02 & 0.11 & $0.07^{*}$ & 0.01 & 0.14 \\
RS $\rightarrow$ PEU $\rightarrow$ SMA & $0.04^{+}$ & 0.01 & 0.08 & $0.05^{*}$ & 0.01 & 0.13
\end{tabular}

Note. ns: not significant, ${ }^{*} \mathrm{p}<0.05,+\mathrm{p}<.10, \mathrm{~L}(\mathrm{U}) \mathrm{B}=$ lower (upper) bound for the bias corrected confidence intervals , Significance levels for indirect effects are two tailed, $\mathrm{PU}=$ perceived usefulness, PEU=perceived ease of use, SMA= social media adoption, $\mathrm{COL}=$ collaboration, $\mathrm{COM}=$ communication and $\mathrm{RS}=$ resource sharing.

The significant direct (see Table 2) and indirect (see Table 3) effects of collaboration (resource sharing) on social media adoption indicate that perceived usefulness and perceived ease of use partially mediate the relationship between (a) collaboration and SMA and (b) resource sharing and SMA, for both samples. Moreover, the indirect effect (see Table 3) of communication, through both the mediating variables, on SMA is significant; whereas, the direct effect (see Table 2) is not significant for the Pakistani sample but it is significant for the Saudi sample. This shows that perceived usefulness and perceived ease of use partially mediate the relationship between communication and SMA for the Saudi sample; whereas, they fully mediate the relationship between communication and SMA for the Pakistani sample. Table 3 reports the unstandardized estimates along with bias-corrected confidence intervals.

The above results thus support the mediating effect of usefulness and ease of use between social media stimuli and its adoption. Hence, $\mathrm{H}_{3} \mathrm{a}, \mathrm{H}_{3} \mathrm{~b}, \mathrm{H}_{4} \mathrm{a}, \mathrm{H}_{4} \mathrm{~b}, \mathrm{H}_{5} \mathrm{a}$, and $\mathrm{H}_{5} \mathrm{~b}$ are all supported. This signifies the important role of ease of use and usefulness of social media in its adoption by the academic community.

\section{Discussion and Implications}

The main purpose of the paper is to investigate the underlying motives behind social media adoption by the academic community. To achieve this, we proposed a conceptual framework by extending the technology acceptance model and social constructivist paradigm. In this extended model, we identified social media features such as collaboration, communication, and resource sharing as the main drivers of social media adoption by the academic community. Along with these social media drivers, we have also incorporated ease of use and usefulness as mediating variables and users' demographics as control variables. Multiple data sources have been used to test the proposed hypotheses and to assess the explanatory power of the proposed conceptual model. After controlling for the respondents' age, gender, and social media usage experience, the results reveal that the data from both countries largely support the proposed concepts. The results establish a significant role of collaboration, communication, and resource sharing in determining a 
users' social media adoption decision. In addition, usefulness and ease of use of social media play a mediating role in the relationship between social media features and social media adoption. Overall, the study provides a significant support for the academic use of social media platforms, and our results are consistent with the literature (Berger, 2017; Sobaih et al., 2016).

The paper contributes to the literature by focusing on the emerging debate of social media adoption by the academic community. This study contributes to the literature on social media adoption by empirically validating the conceptual model on a sample drawn from two developing countries. Additionally, from a theoretical standpoint, the study contributes to the literature by confirming the role of collaboration, communication, and resource sharing in social media adoption, which is in line with the previous research (Mazman \& Usluel, 2010; Sánchez et al., 2014).

Our results significantly support the role of the social learning environmental features of media, including communication, collaboration, and resource sharing, as the predictors of social media adoption in both countries. This shows that the academic community believes that a collaborative learning environment in a social media platform is helpful in establishing improved communication linkage among peers and colleagues.

We also find a significant positive effect of collaboration on perceived usefulness and perceived ease of use. This indicates that the individuals who adopt social media in higher education perceive this medium to be useful and beneficial in collaborating with others, which is aligned with the constructivist view of learning. The result also conforms to the work of Ebner (2009) who found social media platforms, particularly blogs, as a means of collaborative learning for students and teachers independent of time and place.

Social media platforms are capable of developing global networks for academic communities and have the power to change the educational structure by providing a direct channel of communication and collaboration among the community members (Curtis et al., 2010; Waters, Burnett, Lamm, \& Lucas, 2009). This argument can be supported by social constructivism theory and computer-mediated learning (CMC) perspectives. Social constructivist theory stresses on the social interaction and collaboration while CMC supports ubiquity and emphasizes the elimination of geographical barriers. Therefore, to achieve a useful collaborative learning experience, it is necessary to build social communities of practice using collaborative learning environmental capabilities of social media platforms.

So far as the control variables are concerned, the results depict no significant effect of gender or age on social media adoption. However, social media experience is found to have a significant positive effect on social media adoption, which is consistent with the literature (Sánchez et al., 2014).

Although social media platforms are not specifically designed for educational purposes, they do have a great potential for initiating collaboration by facilitating the dissemination of information and sharing resources among the members of the academic community, whom are found to be enthusiastic about social media acceptance and adoption. The question is how social media managers, at the academic institutions, can channelize enthusiasm into actual learning process enhancement. This research will help social media 
managers, in the academic institutions, to devise their strategies for the efficient management of social media platforms.

Higher education institutions should consider the importance of online communities to facilitate academic usage of social media tools. Academic institutions can create their community page on various social media platforms and invite their academic community to become its members. Depending upon the situation, various options of the public (e.g., Twitter, Facebook) or private (e.g., Yammer) social platforms may be used. The community members may be allowed to social sign-on through official email addresses. This will help other community members to search for their peers and collaborate with them.

Academic institutions in developing countries, especially in the public sector, primarily lack modern collaboration and communication tools, such as Blackboard (Sobaih et al., 2016). Effective use of social media platforms can overcome this problem. Moreover, the managers in academic institutions should devise a strategic scenario for ensuring the proper management of social media tools and platforms within a institution. For practitioners, the integration of these social media tools in their teaching and learning process will help improve the teaching and learning experience.

\section{Limitations and Future Research}

The current research enriches our understanding of the social media usage by the academic community; however, in interpreting the findings one should be careful as these may be subject to certain limitations. First, the study has not focused on any particular social media platform rather social media adoption in general. However, an individual's social media adoption levels may vary for different social media platforms due to their personal characteristics as well as social media platforms' features. This will be an interesting future research avenue to explore how social media usage in the academic community varies among different individuals with different backgrounds and on assorted platforms. Second, a cross-sectional data collection has been used in this study, but due to various reasons, the individuals' behavior may change over the time so a longitudinal study can be conducted to overcome this issue. Third, although the model has been tested with samples from two different countries, Pakistan and KSA, there is not much of a difference in demographics between these two countries. Therefore, future research should replicate or extend the proposed conceptual model in technologically advanced countries with different economic and cultural conditions. Fourth, a convenient sampling has been used in the study where future research may address this issue by incorporating other sampling techniques, such as cluster sampling. Fifth, based on the extant literature, we incorporated five dominating variables to explain social media adoption in the conceptual model but many other variables, such as social influence, facilitating conditions, perceived enjoyment, and perceived connectivity, may also play an important role in predicting social media adoption in higher education. Future research may extend this model by incorporating these variables. 


\section{Acknowledgements}

The researchers would like to thank the Deanship of Scientific Research at King Saud University represented by the Research Centre at College of Business Administration for supporting this research financially. 


\section{References}

Berger, P. (2017). Beyond plain acceptance or sheer resistance: A typology of university instructors' attitudes to students' media use in class. Teaching and Teacher Education, 67, 410-417. https://doi.org/10.1016/j.tate.2017.07.009

Bernard, R. M., Rubalcava, B. R. de, \& St-Pierre, D. (2000). Collaborative online distance learning: Issues for future practice and research. Distance Education, 21(2), 260-277. https://doi.org/10.1080/0158791000210205

Bock, G.-W., Zmud, R., Kim, Y.-G., \& Lee, J.-N. (2005). Behavioral Intention formation in knowledge sharing: Examining the Roles of extrinsic motivators, social-psychological forces, and organizational climate. Management Information Systems Quarterly, 29(1).

Chen, B., \& Bryer, T. (2012). Investigating instructional strategies for using social media in formal and informal learning. The International Review of Research in Open and Distributed Learning, 13(1), 87-104.

Chen, H., \& Gilchrist, S. B. (2013). Online access to higher education on YouTubeEDU. New Library World, 114(3/4), 99-109. https://doi.org/10.1108/03074801311304023

Curtis, L., Edwards, C., Fraser, K. L., Gudelsky, S., Holmquist, J., Thornton, K., \& Sweetser, K. D. (2010). Adoption of social media for public relations by nonprofit organizations. Public Relations Review, 36, 90-92. https://doi.org/10.1016/j.pubrev.2009.10.003

Davis, F. D. (1989). Perceived Usefulness, perceived ease of use, and user acceptance of information technology. MIS Quarterly, 13(3), 319-340. https://doi.org/10.2307/249008

Ebner, M. (2009). Introducing live microblogging: How single presentations can be enhanced by the mass. Journal of Research in Innovative Teaching, 2(1), 108-119.

Fishbein, M., \& Ajzen, I. (1975). Belief, attitude, intention and behavior: An introduction to theory and research. Massachusetts, USA: Addison-Wesley Pub (Sd).

Forbes, D. (2017). Professional online presence and learning networks: Educating for ethical use of social media. International Review of Research in Open and Distance Learning, 18(7), 175-190. https://doi.org/10.19173/irrodl.v18i7.2826

Forkosh-Baruch, A., \& Hershkovitz, A. (2012). A case study of Israeli higher-education institutes sharing scholarly information with the community via social networks. The Internet and Higher Education, 15(1), 58-68.

Fornell, C., \& Larcker, D. (1981). Evaluating structural equation models with unobservable variables and measurement error. Journal of Marketing Research, 18(1), 50, 39. 
Gerbing, D. W., \& Anderson, J. C. (1988). An updated paradigm for scale development incorporating unidimensionality and its assessment. Journal of Marketing Research, 25(2), 186. https://doi.org/10.2307/3172650

Gruzd, A., Staves, K., \& Wilk, A. (2012). Connected scholars: Examining the role of social media in research practices of faculty using the UTAUT model. Computers in Human Behavior, 28(6), 2340-2350. https://doi.org/10.1016/j.chb.2012.07.004

Hopp, T., \& Gangadharbatla, H. (2016). Examination of the factors that influence the technological adoption intentions of tomorrow's new media producers: A longitudinal exploration. Computers in Human Behavior, 55, Part B, 1117-1124. https://doi.org/10.1016/j.chb.2014.09.040

Hrastinski, S., \& Aghaee, N. M. (2012). How are campus students using social media to support their studies? An explorative interview study. Education and Information Technologies, 17(4), 451464. https://doi.org/10.1007/s10639-011-9169-5

Hu, L., \& Bentler, P. M. (1999). Cutoff criteria for fit indexes in covariance structure analysis: conventional criteria versus New alternatives. Structural Equation Modeling, 6(1), 1-55.

Hu, P. J. H., \& Hui, W. (2012). Examining the role of learning engagement in technology-mediated learning and its effects on learning effectiveness and satisfaction. Decision Support Systems, 53(4), 782-792. https://doi.org/10.1016/j.dss.2012.05.014

InternetLiveStats. (2018). Internet usage - social media statistics. Retrieved from http://www.internetlivestats.com/

InternetWorldStats. (2018). World internet users and population stats. Retrieved from https://www.internetworldstats.com/stats.htm

Jiang, J. J., Hsu, M. K., Klein, G., \& Lin, B. (2000). E-commerce user behavior model: An empirical study. Human Systems Management, 19(4), 265-275.

Kaplan, A. M., \& Haenlein, M. (2010). Users of the world, unite! The challenges and opportunities of Social Media. Business Horizons, 53(1), 59-68.

Karikari, S., Kofi, O.-F., \& Owusu-Frimpong, N. (2017). Evaluating individual level antecedents and consequences of social media use in Ghana. Technological Forecasting \& Social Change, 123(10), 68-79. https://doi.org/http://dx.doi.org/10.1016/j.techfore.2017.06.023

Koh, E., \& Lim, J. (2012). Using online collaboration applications for group assignments: The interplay between design and human characteristics. Computers \& Education, 59(2), 481-496. https://doi.org/10.1016/j.compedu.2012.02.002

Kwahk, K.-Y., \& Park, D.-H. (2016). The effects of network sharing on knowledge-sharing activities and job performance in enterprise social media environments. Computers in Human Behavior, 55 , 
Part B, 826-839. https://doi.org/10.1016/j.chb.2015.09.044

Lau, W. W. F. (2017). Effects of social media usage and social media multitasking on the academic performance of university students. Computers in Human Behavior, 68, 286-291. https://doi.org/10.1016/j.chb.2016.11.043

Lowry, G. (2002). Modelling user acceptance of building management systems. Automation in Construction, 11(6), 695-705. https://doi.org/10.1016/So926-5805(02)00010-9

Lu, J., Yao, J. E., \& Yu, C.-S. (2005). Personal innovativeness, social influences and adoption of wireless Internet services via mobile technology. The Journal of Strategic Information Systems, 14(3), 245-268. https://doi.org/10.1016/j.jsis.2005.07.003

Macho, S., \& Ledermann, T. (2011). Estimating, testing, and comparing specific effects in structural equation models: The phantom model approach. Psychological Methods, 16(1), 34-43. https://doi.org/10.1037/a0021763

Maresh-Fuehrer, M. M., \& Smith, R. (2016). Social media mapping innovations for crisis prevention, response, and evaluation. Computers in Human Behavior, 54, 620-629. https://doi.org/10.1016/j.chb.2015.08.041

Mazer, J. P., Murphy, R. E., \& Simonds, C. J. (2007). Taylor \& francis online: I'll see you on "Facebook": The effects of computer-mediated teacher self-disclosure on student motivation, affective learning, and classroom climate. Communication Education, 56(1), 1-17.

Mazman, S. G., \& Usluel, Y. K. (2010). Modeling educational usage of Facebook. Computers and Education, 55(2), 444-453. https://doi.org/10.1016/j.compedu.2010.02.008

Mbati, L. (2013). Online social media applications for constructivism and observational learning. The International Review of Research in Open and Distributed Learning, 14(5), 166-185.

Ozkan, S., \& Koseler, R. (2009). Multi-dimensional students' evaluation of e-learning systems in the higher education context: An empirical investigation. Computers \& Education, 53(4), 1285-1296. https://doi.org/10.1016/j.compedu.2009.06.011

Podsakoff, P. M., MacKenzie, S. B., Lee, J.-Y., \& Podsakoff, N. P. (2003). Common method biases in behavioral research: a critical review of the literature and recommended remedies. The Journal of Applied Psychology, 88(5), 879-903. https://doi.org/10.1037/0021-9010.88.5.879

Prensky, M. (2001). Digital natives, digital immigrants, part II. Do they really think differently? On the Horizon, 9(6), 1-6.

Roblyer, M. D., McDaniel, M., Webb, M., Herman, J., \& Witty, J. V. (2010). Findings on Facebook in higher education: A comparison of college faculty and student uses and perceptions of social networking sites. Internet and Higher Education, 13(3), 134-140. 
https://doi.org/10.1016/j.iheduc.2010.03.002

Sánchez, R. A., Cortijo, V., \& Javed, U. (2014). Students' perceptions of Facebook for academic purposes. Computers \& Education, 7o(1), 138-149. https://doi.org/10.1016/j.compedu.2013.08.012

Selwyn, N. (2012). Social media and higher education. In The Europa World of Learning. London, UK: Routledge.

So, H.-J., \& Brush, T. A. (2008). Student perceptions of collaborative learning, social presence and satisfaction in a blended learning environment: Relationships and critical factors. Computers \& Education., 51(1), 318-336. https://doi.org/10.1016/j.compedu.2007.05.009

Sobaih, A. E. E., Moustafa, M. A., Ghandforoush, P., \& Khan, M. (2016). To use or not to use? Social media in higher education in developing countries. Computers in Human Behavior, 58, 296-305. https://doi.org/10.1016/j.chb.2016.01.002

Tess, P. A. (2013). The role of social media in higher education classes (real and virtual) - A literature review. Computers in Human Behavior, 29(5), A60-A68. https://doi.org/10.1016/J.CHB.2012.12.032

Venkatesh, V. (2000). Creation of favorable user perceptions: Exploring the role of intrinsic motivation. MIS Quaterly., 23(2), 239-260. https://doi.org/10.2307/249753

Venkatesh, V., \& Davis, F. D. (2000). A theoretical extension of the technology acceptance model: Four longitudinal field studies. Management Science, 46(2), 186-204. https://doi.org/<p>10.1287/mnsc.46.2.186.11926</p >

Vygotsky, L. S. (1978). Mind in society: The development of higher psychological processes. Cambridge, MA: Harvard University Press.

Wang, Q. (2010). Using online shared workspaces to support group collaborative learning. Computers \& Education, 55(3), 1270-1276. https://doi.org/10.1016/j.compedu.2010.05.023

Wankel, C. (2009). Management education using social media. Organization Management Journal, 6(4), 251-262. https://doi.org/10.1057/omj.2009.34

Waters, R. D., Burnett, E., Lamm, A., \& Lucas, J. (2009). Engaging stakeholders through social networking: How nonprofit organizations are using Facebook. Public Relations Review, 35(2), 102-106. https://doi.org/10.1016/j.pubrev.2009.01.006

Zolkepli, I. A., \& Kamarulzaman, Y. (2015). Social media adoption: The role of media needs and innovation characteristics. Computers in Human Behavior, 43, 189-209. https://doi.org/10.1016/j.chb.2014.10.050 


\section{Appendix A}

\section{Questionnaire}

\begin{tabular}{|c|c|}
\hline Construct & \\
\hline Usefulness & $\begin{array}{l}\text { Davis (1989) and Venkatesh and Davis (2000): } \\
\text { - I find Social Media useful in my studies/research. } \\
\text { - } \quad \text { Using Social Media enables me to accomplish tasks more quickly. } \\
\text { - } \quad \text { Using Social Media increases my productivity. } \\
\text { - If I use Social Media, it will increase my chances of getting a better } \\
\quad \text { position. }\end{array}$ \\
\hline Ease Of Us & $\begin{array}{l}\text { Davis (1989) and Venkatesh and Davis (2000): } \\
\text { - My interaction with Social Media is clear and understandable. } \\
\text { - It is easy for me to become skillful at using Social Media. } \\
\text { - I find Social Media easy to use. } \\
\text { - Learning to operate Social Media is easy for me. } \\
\text { from Ozkan and Koseler (2009): }\end{array}$ \\
\hline & $\begin{array}{l}\text { - Social Media makes the communication easier with instructor/colleagues } \\
\text { and other classmates for me. } \\
\text { - I think communicating with the instructor/colleagues via Social Media is } \\
\text { important and valuable. } \\
\text { - The instructor/colleague encourages us/me to interact with other } \\
\text { students/colleagues by using Social Media interactive tools. } \\
\text { - The instructor/colleagues are good at communicating with each other via } \\
\text { Social Media. }\end{array}$ \\
\hline \multirow{2}{*}{\multicolumn{2}{|c|}{$\begin{array}{l}\text { Collaborative learning adapted from So and Brush (2008): } \\
\qquad \quad \text { I actively exchange my ideas with group members. } \\
\bullet \quad \text { I can develop new skills and knowledge from other members of my } \\
\text { group. } \\
\bullet \quad \text { Collaborative learning by using Social Media is effective. } \\
\bullet \quad \text { Overall, I am satisfied with my collaborative learning experience by using } \\
\quad \text { Social Media. }\end{array}$}} \\
\hline & \\
\hline \multicolumn{2}{|c|}{$\begin{array}{l}\text { - Sharing of my knowledge with other members of Social Media is always } \\
\text { good. } \\
\text { Sharing of my knowledge with other members of Social Media is always } \\
\text { beneficial. } \\
\text { - Sharing of my knowledge with other members of Social Media is always } \\
\text { an enjoyable experience. } \\
\text { - Sharing of my knowledge with other members of Social Media is always a } \\
\text { wise move. }\end{array}$} \\
\hline Social med & $\begin{array}{l}\text { adapted from Bock et al. (2005): } \\
\text { - } \quad \text { I intend to adopt Social Media for knowledge sharing. } \\
\text { - } \quad \text { I predict that I would adopt Social Media for knowledge sharing. } \\
\text { - } \quad \text { I plan to continue using Social Media for knowledge sharing. } \\
\text { - I will continue using Social Media for knowledge sharing. }\end{array}$ \\
\hline
\end{tabular}


Social Media Adoption by the Academic Community: Theoretical Insights and Empirical Evidence From Developing Countries Arshad and Akram

Athabasca

University

(c) (1)

BY 